\title{
Call for Nomination of Members of the International Standing Committee of Human Cytogenomic Nomenclature
}

The present Committee (Jaclyn Biegel, Myriam Chaabouni, Johan T. den Dunnen, Jin-Yeong Han, Nils Mandahl, Jean McGowan-Jordan, Kathleen W. Rao, Annet Simons) was elected in the fall of 2011, with Lisa Shaffer as Chair. The Committee elected a new Chair, Jean McGowan-Jordan, during their meeting in Seattle in 2012. Several new members of the Committee now need to be elected. To facilitate continuity and maintain geographic distribution, the Chair of the new Committee will remain, along with Nils Mandahl, Johan T. den Dunnen, and Jin-Yeong Han. New members from the Americas (2), Europe (1), Africa and Australia/New Zealand/Oceania (1) are therefore required.

The nominations of potential new Committee members shall be by e-mail. Nominations for candidates including their name, affiliation, postal address and e-mail address should be e-mailed to the Chair at jordan@cheo.on.ca before February 15, 2018, after which the list of nominated candidates will be published with the call for voting. Ballots for voting can be requested from the Chair at jordan@cheo.on.ca after February 15, 2018, by including your name, affiliation, postal address, and e-mail. The election ballots with voting procedures will then be distributed after March 15, 2018, to the requested address. Instructions for returning the ballots will accompany the ballot requests. 